\title{
An Overview of Post-COVID-19 Patient's Health Monitoring Systems
}

\author{
Chirag Satapathy ${ }^{1}$, Hrishikesh Gokhale ${ }^{2}$, Ali Zoya Syed ${ }^{3}$, Keerti Srivastava ${ }^{4}$ and Ruban Nersisson
}

School of Electrical Engineering, Vellore Institute of Technology, Vellore, Tamil Nadu, India

To Cite this Article

Chirag Satapathy, Hrishikesh Gokhale, Ali Zoya Syed, Keerti Srivastava and Ruban Nersisson. An Overview of Post-COVID-19 Patient's Health Monitoring Systems. International Journal for Modern Trends in Science and Technology 2021, 7 pp. 61-67. https://doi.org/10.46501/IJMTST0710010

\section{Article Info}

Received: 11 September 2021; Accepted: 01 October 2021; Published: 04 October 2021

\section{ABSTRACT}

COVID-19 is a global pandemic infecting human life. There are many patients who have recovered from this deadly virus and need to be monitored constantly even when they are at home. IoT plays a vital role in health systems that help to monitor patient's health conditions. These healthcare frameworks consist of smart sensors to keep a track of patient's vitals on a real-time basis. These systems will help bridge gaps between the patients and doctors during the pandemic situation. In order to make our system competitive against the already existing devices, we prepared a comprehensive review where we extensively studied other products and compared them to find what's best for the patients.

KEYWORDS: COVID-19, Healthcare, Internet of Things, Pandemic, Real-time, Smart Sensors

\section{INTRODUCTION}

IOT (Internet of Things) is a network of physical devices that uses connectivity to enable the exchange of data. IoT has many applications like smart cities, home automation, remote healthcare monitoring, smart agriculture and many more. The current dire situation faced by the world is the COVID-19 pandemic. COVID also known as Coronavirus Disease is a virus that affects people by infecting their lungs and causes trouble in breathing. Many people have been infected by this deadly virus. Also, many people have recovered by this disease and are sent back home. But their body vitals still need to be monitored constantly under surveillance as their body would be weak.

To help the post-covid patients, we have combined IoT with healthcare sensors and GSM modules to keep a track of patients remotely. This system is a low-cost system that is embedded with various sensors like SP02, pulse and temperature. These vitals are tracked every hour and are stored on cloud working on real-time basis. The GSM module is provided to alert the doctors in-charge of their patients if the patients vitals are unstable. The healthcare systems works better and more suitable by integrating both IoT and GSM together for patient monitoring [1].

K Aziz's algorithm to use GSM and GPS module together in a healthcare monitoring system is unique as it compares the minimum and maximum values stored in the microcontroller and alerts the doctor or person in charge of the patient with all the patients details and location so that it makes the doctor track the patient immediately during an

emergency [2]. For the ventilator to be inexpensive and minimize its complexity, El Majid, designed a ventilator based on unidirectional motion to maximize its availability [3]. 


\section{RELATED WORK}

The coronavirus disease mostly affects the lungs of human beings and hence cause difficulty in breathing. Due to this a lot of infected patients required the help of ventilator support to breathe and thus the production of ventilators is in dire demand during this scenario. El Majid, proposed and designed a unidirectional motion-based ventilator which minimizes the complexity of their production and can be produced easily [4].

On the other hand, Ghafoor, designed two prototypes of ventilator before deciding of the final design of the prototype. The first ventilator design was a double arm concept which uses two iron arms to press the BVM in between. This design was considered at first but wasn't used as there was heating up of the motor and made the ventilator heavy which wouldn't be portable. The second prototype was based on a single arm mechanism. This reduced the heat production on the motor and also made it potable. This prototype was later upgraded using pressure sensors to control motion of the motor and also equipped with a brightness-controlled LCD [5].

The proposed paper on IoT based healthcare monitoring system by $\mathrm{V}$. Tamilselvi is connecting all the smart health sensors (temperature, pulse, SP02) to an Arduino Uno board which is connected to a Wi-Fi and a GSM module with the help of IoT to send and receive data. Thingspeak software was used for SMS. Also, for motion tracking of patients, accelerometer is used to keep track of body movement [1].

The paper by K. Aziz proposes a smart healthcare monitoring and tracking system that tracks the patient's vitals as well as their location on real-time. All the heath sensors are connected to Arduino that is further connected to a GPS and GSM module. This system is a smart board attached to a patient's body. Also, Arduino Lilypad is used to connect sensors to it and then can be sewn into clothing [2].

Vedaei, designed a high-level post-covid pandemic framework to track patient's vitals as well the distance between various zones of people till the pandemic zone. This system works with IoT, Bluetooth and based ML data processing on cloud. The patient will wear an IoT device with RPIZ (Raspberry-pie zero) that tracks their temperature, pulse and $\mathrm{SPO} 2$ and send data to a smartphone app via Bluetooth. All these data are then sent to the server via mobile data network or Wi-Fi. Also, this system has a second mode when mobile networks don't operate which can be seen in rural areas. Here a LoRa-based network is used [3].

In the paper 'ZigBee and GSM Based Patient Health Monitoring System [6]' paper, the authors used the following hardware: ARM processor (for low power consumption), ECG sensor (to measure ECG signals), LM35 (to measure temperature), ADXL213 (Accelerometer to determine whether the patient is in stable condition (standing or sitting) or has fallen down), and a heartbeat sensor.

The authors have used Embedded Linux to program the ARM processor, MySQL database for data storage and Visual Studio for the Graphical User Interface.

In the paper 'Internet of Thing based Healthcare monitoring system [7]', the authors have used the following hardware: Arduino UNO, ESP8266 Wi-Fi module, GSM modem (for SMS service), ECG sensor, Heartbeat sensor, LM35 temperature sensor, LCD display (to display the readings) and a piezoelectric buzzer (buzzes when the readings are abnormal). The authors have used Embedded $\mathrm{C}$ and Hi-Tech C compiler for programming the microcontroller and have used HTML (Hyper Text Markup Language) to provide an interface for the doctor to continuously monitor the patient's readings.

In the paper 'An Embedded, GSM based, Multiparameter, Real time Patient Monitoring System and Control - An Implementation for ICU Patients [8]', the authors have used the following hardware: LM35 temperature sensor, GSM module, Heart rate sensor, Blood pressure sensor and AtMega32 as the microcontroller using Embedded $\mathrm{C}$ as the programming language. The system allows doctors and their subordinates to communicate regarding the condition of the patient, and to plan necessary steps of action.

In the paper 'A Hospital Healthcare Monitoring System Using Wireless Sensor Networks [9], the authors have used the following hardware: WBSN (Wireless Body Sensor Network) which consists of Heart rate sensor, Blood pressure sensor, Accelerometer sensor and GSM module. This system has been developed in multi-system architecture and outperforms its competitors with respect to power consumption and speed. 
In the paper 'A Wireless Sensor Network Compatible Wearable U-healthcare Monitoring System Using Integrated ECG, Accelerometer and SpO2 [10], the authors have used the following hardware: ECG sensor, accelerometer, $\mathrm{SPO} 2$ sensor, wireless transceiver (CC2420), A/D convertor (embedded MSP430F1611) and the low-power consuming MSP430 as the microcontroller.

Michael Rockwood, Vilas Joshi, Kevin Sullivan, Rafik Goubran, IEEE Department of Systems and Computer Engineering, Carleton University, Ottawa, Canada: This paper evaluates the performance of a real-time operating system (RTOS)-based multi-sensor RPM system. The real-time system performance is measured against a hard real-time processing threshold for five simulated sensor inputs with varying priority levels [11].

Sandesh Chinchole, Laksh Matai, Sinhgad Institute of Technology Navi Mumbai, India: The system presented in the paper utilizes the mobile internet, serverless technology and cloud computing to serve unliterate people. The system acts as a picture centered real-time messaging system to enable the people to order medication online and get it delivered to their residences [12].

The paperobserved the effects of mobile phone on intensive care units. Electromagnetic interference (EMI) was tested by the mobile phone's network properties. Mobile phones were placed at a distance of one foot from three medical devices - syringe pump, bedside monitor and mechanical ventilator in standby, switch off and talking modes of the phone. Medical devices were observed for any interference caused by the radiations (EMR) from the mobile phones [13].

"IoT Based Remote Health Monitoring System for Patients and Elderly People" uses architecture of IoT, Principle of Photoplethysmography and galvanic skin response. Just like all the existing devices, this utilizes both hardware as well as software. In the hardware portion, the Arduino Uno and Raspberry Pi were used for detection and storage on cloud. The software portion of any healthcare system is the brain for the controls. Thus, the system included everything starting from the use of micro-controller IDE to the use of Android development Tool Kit which made up the architecture of the device. The data extraction was done by Arduino
IDE while the Raspberry Pi stored all the data on the cloud [14].

The paper by Kaaviya Baskaran put forth for understanding the various alternatives we have in order to prevent hassle as well as ensure healthy environment in work place. With IR sensing and thermal sensing this system recognized the various employees, ensured safety by analyzing if the employee is wearing a mask as well as stored every data in the database for further analysis. This device was an accumulation of multiple health and attendance management. It performed processing on all the input and generated the response in the form of buzzer notification and blinking of the LED lights. Raspberry Pi3 + could also be connected to the Wi-fi system for surveillance purposes [15].

Positive-pressure ventilators work by increasing the airway pressure through a tracheostomy tube and allows air to flow into the airway until the ventilator breath is terminated. The research paper dealt with the data to understand the merits and demerits of using a mechanical ventilator during the COVID period keeping in mind the stature of the patients as well as the well-being of the health workers [16].

\section{COMPARISION OF DIFFERENT APPROACHES}

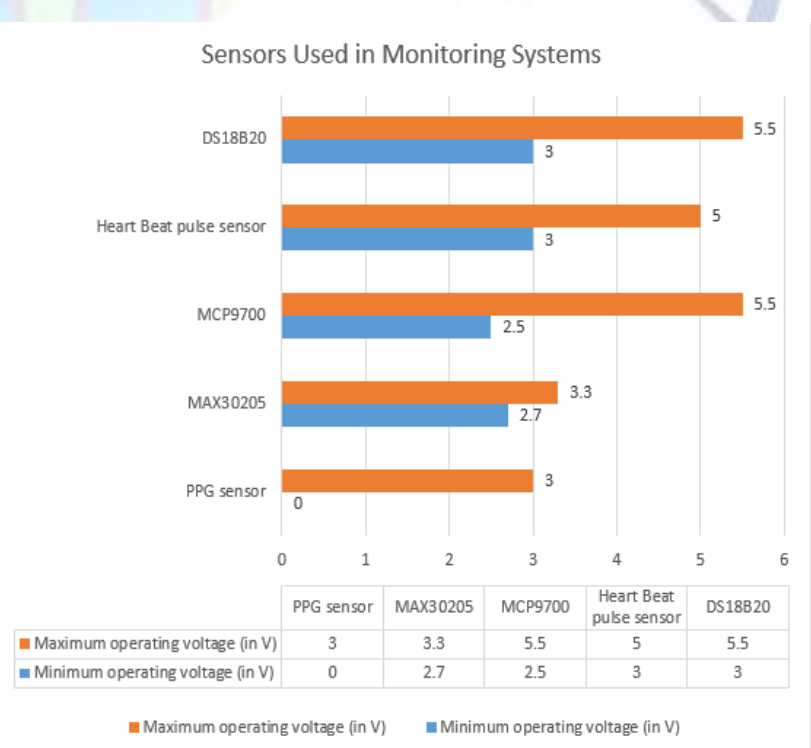

Fig. 1. Operating voltage of various sensors used

Looking at Figure 1, studies show that a higher voltage system is more efficient than a lower voltage system since its experiences less energy loss from resistance given that the power drawn is the same. We 
can see that MCP700 and DS18B20 have the highest maximum operating voltage of $5.5 \mathrm{~V}$, which means these sensors can work with maximum voltage supply of up to $5.5 \mathrm{~V}$

TABLE I. CONCEPTS OF VENTILATORS

\begin{tabular}{|l|l|l|l|}
\hline Reference & $\begin{array}{l}\text { Ventilator } \\
\text { Concept }\end{array}$ & Microcontroller & Pressure Sensor \\
\hline$[3]$ & $\begin{array}{l}\text { Single arm } \\
\text { concept }\end{array}$ & Arduino Mega & Analog pressure \\
\hline$[4]$ & $\begin{array}{l}\text { Unidirectional } \\
\text { motion }\end{array}$ & Arduino/ ESP33 & MPXV5050GP \\
\hline
\end{tabular}

From Table I, the single arm ventilator concept, uses a single metal arm to squeeze an Ambu bag. The Ambu bag is placed between wooden boards. With the help of a DC motor, the metal arm compresses the Ambu and the pressure is maintained with the help of analog pressure sensor [4].

The unidirectional motion-based ventilator is built using plastic air tank attached to two circular disks with a bendable wire connected in between. Here the pressure sensor used is MPXV5050GP that is a low-cost sensor to measure the pressure in the air tank. The working of this ventilator is simple. The DC motor attached on the top circular disk rotates and causes the wire to bend that in turn pulls the bottom circular disk towards the top, hence compressing the air tank.

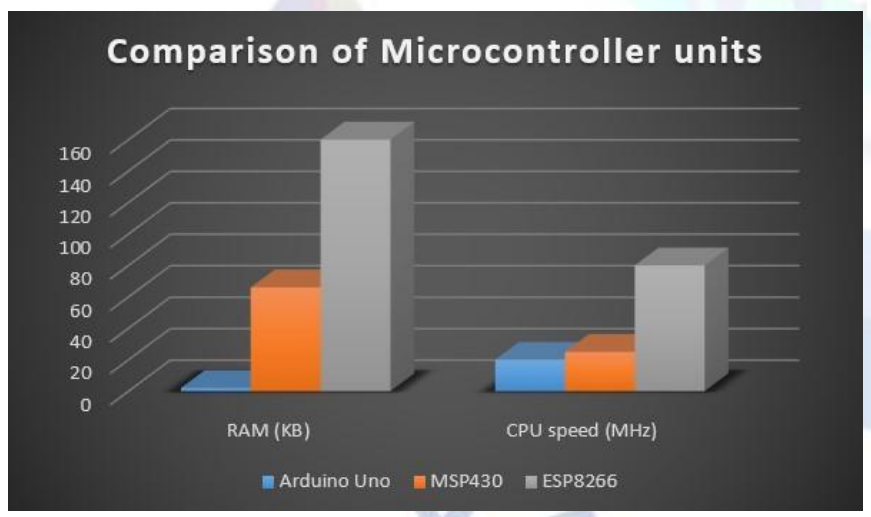

Fig. 2. Comparison of microcontroller units

The given chart in Figure 2 compares the following properties of the three microcontroller units taken into consideration:

\section{CPU speed}

\section{RAM}

As we can clearly make out, ESP8266 has the highest RAM capacity and CPU speed, followed by the MSP430. Arduino UNO and AtMega328p fall behind in these attributes.

TABLE II. MICROCONTROLLERS USED

\begin{tabular}{|l|l|l|l|}
\hline $\begin{array}{l}\text { Name of } \\
\text { Microcontroller }\end{array}$ & $\begin{array}{l}\text { Operating } \\
\text { Voltage (V) }\end{array}$ & $\begin{array}{l}\text { RAM } \\
\text { (KB) }\end{array}$ & $\begin{array}{l}\text { CPU } \\
\text { Speed } \\
\text { (MHz) }\end{array}$ \\
\hline Arduino Uno & 5 & 2 & 20 \\
\hline MSP430 & 1.8 & 66 & 25 \\
\hline ESP8266 & 5 & 160 & 80 \\
\hline
\end{tabular}

From Table II, we can see that the MSP430 operating voltage is very low, making it an attractive option for such systems.

\section{TABLE III. HEALTH SYSTEMS COMPARISION}

\begin{tabular}{|c|c|c|c|c|c|c|}
\hline Ref & $\begin{array}{l}\text { Har } \\
\text { dwa } \\
\text { re } \\
\text { offer } \\
\text { ed? }\end{array}$ & $\begin{array}{l}\text { Diag } \\
\text { nosi } \\
\text { s }\end{array}$ & $\begin{array}{l}\text { Noti } \\
\text { ficat } \\
\text { ion } \\
\text { to } \\
\text { pers } \\
\text { on/ } \\
\text { Hosp } \\
\text { ital }\end{array}$ & $\begin{array}{l}\text { Updat } \\
\text { e on } \\
\text { real-ti } \\
\text { me } \\
\text { basis? }\end{array}$ & $\begin{array}{l}\text { Sensors } \mathcal{E} \\
\text { Microcontr } \\
\text { ollers } \\
\text { Present }\end{array}$ & $\begin{array}{l}\text { Rem } \\
\text { ote } \\
\text { mon } \\
\text { i- } \\
\text { tori } \\
\text { ng }\end{array}$ \\
\hline [1] & $\begin{array}{l}\text { Yes } \\
\text { (dev } \\
\text { elop } \\
\text { men } \\
\text { t kit) }\end{array}$ & Yes & $\begin{array}{l}\text { Yes, } \\
\text { Yes }\end{array}$ & Yes & $\begin{array}{l}\text { MAX30205, } \\
\text { HBS, EBS, } \\
\text { SP02, } \\
\text { ADX345 }\end{array}$ & Yes \\
\hline [2] & $\begin{array}{l}\text { Yes } \\
\text { (sma } \\
\text { rt } \\
\text { wea } \\
\text { rabl } \\
\text { e } \\
\text { ban } \\
\text { d) }\end{array}$ & Yes & $\begin{array}{l}\text { Yes, } \\
\text { Yes }\end{array}$ & Yes & $\begin{array}{l}\text { Arduino } \\
\text { Uno, GSM, } \\
\text { Lilypad, } \\
\text { MCP9700, } \\
\text { Heart beat } \\
\text { pulse sensor }\end{array}$ & Yes \\
\hline [3] & $\begin{array}{l}\text { Yes } \\
\text { (sma } \\
\text { rtph } \\
\text { one } \\
\text { and } \\
\text { sens } \\
\text { ors) }\end{array}$ & $\begin{array}{l}\text { Yes } \\
\text { (per } \\
\text { sona } \\
1 \\
\text { and } \\
\text { regi } \\
\text { onal } \\
\text { ) }\end{array}$ & $\begin{array}{l}\text { Yes, } \\
\text { Yes }\end{array}$ & Yes & $\begin{array}{l}\text { RPIZW, } \\
\text { LoRa, } \\
\text { Temperatur } \\
\text { e sensor }\end{array}$ & Yes \\
\hline [6] & $\begin{array}{l}\text { Yes } \\
\text { (sma } \\
\text { rtph } \\
\text { one } \\
\text { and } \\
\text { sens } \\
\text { ors) }\end{array}$ & Yes & $\begin{array}{l}\text { Yes, } \\
\text { Yes }\end{array}$ & Yes & $\begin{array}{l}\text { ARM } \\
\text { processor, } \\
\operatorname{lm} 35, \\
\text { ADXL213, } \\
\text { ECG, HBS }\end{array}$ & Yes \\
\hline
\end{tabular}




\begin{tabular}{|c|c|c|c|c|c|c|}
\hline [7] & $\begin{array}{l}\text { Yes } \\
\text { (dev } \\
\text { elop } \\
\text { men } \\
t \text { kit) }\end{array}$ & Yes & $\begin{array}{l}\text { Yes, } \\
\text { Yes }\end{array}$ & Yes & $\begin{array}{l}\text { Arduino } \\
\text { Uno, GSM, } \\
\text { ESP8266, } \\
\text { ECG, HBS, } \\
\text { LM35, PE } \\
\text { Buzzer }\end{array}$ & Yes \\
\hline [8] & $\begin{array}{l}\text { Yes } \\
\text { (sma } \\
\text { rtph } \\
\text { one } \\
\text { and } \\
\text { sens } \\
\text { ors) }\end{array}$ & $\begin{array}{l}\text { Yes } \\
\text { (regi } \\
\text { onal } \\
\text { ) }\end{array}$ & $\begin{array}{l}\text { Yes, } \\
\text { Yes }\end{array}$ & Yes & $\begin{array}{l}\text { LM35, GSM, } \\
\text { HRS, Blood } \\
\text { pressure } \\
\text { sensor, } \\
\text { AtMega } 32\end{array}$ & Yes \\
\hline [9] & A) & $\begin{array}{l}\text { Yes } \\
\text { (per } \\
\text { sona } \\
1 \\
\text { and } \\
\text { regi } \\
\text { onal } \\
\text { ) }\end{array}$ & $\begin{array}{l}\text { Yes, } \\
\text { Yes }\end{array}$ & Yes & $\begin{array}{l}\text { HRS, } \\
\text { Acceleromet } \\
\text { er, GSM }\end{array}$ & Yes \\
\hline$y$ & $\begin{array}{l}\text { Yes } \\
\text { (dev } \\
\text { elop } \\
\text { men } \\
\text { t kit } \\
\text { and } \\
\text { sens } \\
\text { ors) }\end{array}$ & Yes & $\begin{array}{l}\text { Yes } \\
\text { (base } \\
\text { stati } \\
\text { on) }\end{array}$ & Yes & $\begin{array}{l}\text { Integrated } \\
\text { ECG, } \\
\text { Acceleromet } \\
\text { er, SP02, } \\
\text { MSP430, } \\
\text { USN }\end{array}$ & Yes \\
\hline [12] & $\begin{array}{l}\text { Yes( } \\
\text { sma } \\
\text { rtph } \\
\text { one) }\end{array}$ & $\begin{array}{l}\text { Yes( } \\
\text { pers } \\
\text { onal } \\
\text { ) }\end{array}$ & Yes & Yes & $\begin{array}{l}\text { Arduino } \\
\text { Uno, R-Pi }\end{array}$ & Yes \\
\hline [14] & $\begin{array}{l}\text { Yes } \\
\text { (dev } \\
\text { elop } \\
\text { men } \\
t \text { kit) }\end{array}$ & $\begin{array}{l}\text { Yes( } \\
\text { regi } \\
\text { onal } \\
\text { ) }\end{array}$ & $\begin{array}{l}\text { Yes, } \\
\text { Yes }\end{array}$ & Yes & $\begin{array}{l}\text { QR code } \\
\text { scanner, } \\
\text { R-Pi, IR } \\
\text { sensor, } \\
\text { Webcam }\end{array}$ & Yes \\
\hline
\end{tabular}

From Table III, we deduce that the COVID SAFE system proposed by Vedaei, is the best system overall with most features and performance. This system also gives COVID symptoms with distance measurement by dividing distances into zones. Equipped with the long-range WAN that helps transmit data even from rural places. Works on real-time basis too.

\section{RESULT COMPARISION}

\section{A. Polytechnic University of Madrid (UPM):}

In IoT space there are usually many different technical alternatives for healthcare applications, which means that the concrete projects should analyze the whole set of main possible solutions in order to determine the optimal ones, considering the particular constrains and priorities of the corresponding applications. Therefore, it is important to have a structured system engineering methodology to guide the corresponding decision processes for developing Health-IoT ecosystems [17].

\section{B. Carleton University:}

Real-time remote monitoring is becoming increasingly popular as mobile processing power becomes cheaper. This will allow the use of multiple sensors to monitor a variety of chronic and acute conditions simultaneously. Using high sampling rate sensors like video, audio, or multi-channel ECG/EEG along with complex signal processing algorithms will significantly increase the processor workload, and may lead to starvation of real-time critical tasks. An RPM system based on an RTOS can prioritize the time critical tasks to ensure that alarms are generated in a timely manner [11].

\section{Fudan University:}

In this paper, a bio-potential signals monitoring healthcare system composing of Analog Front End and SRD Transceiver is introduced. The system is designed with low power consumption and flexible configuration, capable of monitoring ECG signals wirelessly at real-time. Experimental results show that the proposed system is portable for people to monitor health [18].

\section{Sinhgad Institute of Technology, University of Texas and New York University:}

The system fundamentally performed two main tasks of sending image focused request and response messages between the users and the pharmacists. The work showcased in this paper achieved our aim to build a user-friendly system which would enable the illiterate and people with low visual impairment to order medication online and get it delivered to their residence. The major advantages of the system included swiftness, simple UI of the applications and efficiency [12].

\section{E. University Malaysia Sabah Kota Kinabalu:}

The proposed system can be applied in the hospital. The doctors or nurses can observe the ECG signal of any patients at any time any place through the computer or smartphone, without going to the wards. This system is able to reduce the patients' traveling time and cost especially for those patients who are from sub-urban or 
rural areas. Doctors can monitor the ECG of the chronic cardiac patient in distance via the internet. The proposed system has the potential of improving the quality of healthcare services all over the nation. The data recorded by various devices can even help in surveillance and well-being of the employees thereby increasing the producibility. The ventilators now in use can be made more effective by deploying the unnecessary factors thereby increasing the patient as well as staff safety. The heath monitoring systems can be put into use and can serve a large proportion of people thereby helping in daily monitoring and early detection of various parameter [19].

These papers as mentioned describe patient-device interaction and physical factors that influence the entire working of these devices. The post COVID measures to be kept into mind may include IoT based verifications, better treatment devices and wireless devices that compute the data within milliseconds and reserves the data for further examination. The producibility of the devices can be increased by a major extent by replacing components by cheap and effective components and thus making the healthcare system affordable to wider range of the population.

Hence from all papers, we can deduce some advantages regarding wireless patient monitoring system. They are as follows:

1. Easy and reliable for doctors - Wireless monitoring eliminates the need for doctors or nurses to move around physically to check the patients' health. Thus, critical situations can be found easily since the health of the patient is monitored at every moment.

2. The number of nurses required to monitor patients is also greatly reduced, which can increase efficiency in the hospital.

3. Chances of human error are also greatly reduced when such a system is put in place and thus the accuracy of the readings obtained is increased.

\section{ABBREVIATIONS}

1. HRS - Heart Rate Sensor

2. GSM - Global System for Mobile Communication

3. HBS - Heart Beat sensor

4. EBS - Eye Blink sensor
5. RPIZW - Raspberry Pi Zero

6. LoRa - Long Range technology

7. SP02-Oxygen saturation

8. ECG - Electrocardiography (heart monitor)

9. ARM - Advanced RISC machine

10. RISC - Reduced Instruction set computer

11. USN - Unified serving node

12. WAN - Wide area network

\section{CONCLUSION}

Real time data and context information provided by wearable medical devices with associated electronic health records can be extremely valuable assets for caregivers and a significant source for scientists, since they have the possibility to easily capture continuous patient data and context information outside the facility walls. This can be accomplished by prescribing medical devices that can monitor and securely store health information to a central repository or cloud, which provide continuous flows of information for extended periods of time, in order to achieve real predictive healthcare and also for detecting possible unhealthy habits.

After studying these papers, we found that these technologies are sufficient for monitoring the patient and for sending alerts and messages to both relatives as well as doctors if anything was to go wrong. However, we found that none of them had an emergency system which could be operated by the patient in a time of crisis. To address this issue, we decided to add a basic ventilator system to our project which could help buy valuable time in an emergency situation.

\section{REFERENCES}

[1] T. V, S. S, V. P, V. P and G. J, "IoT Based Health Monitoring System," in 6th International Conference on Advanced Computing \& Communication Systems (ICACCS), 2020.

[2] K. Aziz, S. Tarapiah, S. H. Ismail and S. Atalla, "Smart Real-Time Healthcare Monitoring and Tracking System using GSM/GPS Technologies," in 3rd MEC International Conference on Big Data and Smart City, 2016.

[3] S. S. Vedaei, A. Fotovvat, M. R. Mohebbian, G. M. Rahman, K. A. Wahid, P. Babyn, H. R. Marateb, M. Mansourian and R. Sami, "COVID-SAFE: An IoT-based System for Automated Health Monitoring and Surveillance in Post-Pandemic Life," IEEE Access, vol. 8, pp. 188538 - 188551, 2020.

[4] B. E. Majid, A. E. Hammoumi, S. Motahhir, A. Lebbadi and A. E. Ghzizal, "Preliminary design of an innovative, simple, and easy 
to build portable ventilator for COVID 19 patients," Euro-Mediterranean Journal for Environmental Integration, 2020.

[5] M. J. Ghafoor, M. Naseem, F. Ilyas, M. S. Sarfaraz, M. I. Ali and A. Ejaz, "Prototyping of a Cost Effective and Portable Ventilator," in International Conference on Innovations in Electrical Engineering and Computational Technologies (ICIEECT), Karachi, Pakistan, 2017.

[6] P. P. Singh, "Zigbee and GSM based patient health monitoring system," in International Conference on Electronics and Communication Systems (ICECS), 2014.

[7] H. N. Saha, D. Paul, S. Chaudhry, S. Haldar and R. Mukherjee, "Internet of Thing based healthcare monitoring system," in 8th IEEE Annual Information Technology, Electronics and Mobile Communication Conference (IEMCON), Vancouver, BC, Canada, 2017.

[8] N. P. Jain, P. N. Jain and T. P. Agarkar, "An embedded, GSM based, multiparameter, realtime patient monitoring system and control - An implementation for ICU patients," in World Congress on Information and Communication Technologies, Trivandrum, India, 2012.

[9] M. Aminian and H. R. Naji, "A Hospital Healthcare Monitoring System Using Wireless Sensor Networks," Journal of Health \& Medical Informatics, vol. 04, 2013.

[10] W.-Y. Chung, Y.-D. Lee and S.-J. Jung, "A wireless sensor network compatible wearable u-healthcare monitoring system using integrated ECG, accelerometer and SpO2," in 30th Annual International Conference of the IEEE Engineering in Medicine and Biology Society, Vancouver, BC, Canada, 2008.

[11] M. Rockwood, V. Joshi, K. Sullivan and R. Gourban, "Using a real-time operating system for multitasking in Remote Patient Monitoring," in IEEE International Symposium on Medical Measurements and Applications (MeMeA), Lisboa, Portugal, 2014.

[12] N. Hans and F. N. Kapadia, "Effects of mobile phone use on specific intensive care unit devices," Indian Journal of Critical Care Medicine, vol. 12, pp. 170-3, 2008.

[13] M. Hamim, S. Paul, S. I. Hoque, M. N. Rahman and I.-A. Baqee, "IoT Based Remote Health Monitoring System for Patients and Elderly People," in International Conference on Robotics,Electrical and Signal Processing Techniques (ICREST), Dhaka, Bangladesh, 2019.

[14] E. Kondili, G. Prinianakis and D. Georgopoulos, "Patient-ventilator interaction," British journal of anaesthesia, vol. 91, no. 1, pp. 106-119, 2003.

[15] K. Baskaran, P. Baskaran, V. Rajaram and N. Kumaratharan, "IoT Based COVID Preventive System for Work Environment," in Fourth International Conference on I-SMAC (IoT in Social, Mobile, Analytics and Cloud) (I-SMAC), Palladam, India, 2020.

[16] R. Tiruvoipati and J. Botha, "Fighting a pandemic with mechanical ventilators," Internal Medicine Journal, vol. 50, no. 8, pp. 1019-1020, 2020.

[17] F. Fernandez and G. C. Pallis, "Opportunities and challenges of the Internet of Things for healthcare: Systems engineering perspective," in 4th International Conference on Wireless Mobile Communication and Healthcare - Transforming Healthcare Through Innovations in Mobile and Wireless Technologies (MOBIHEALTH), Athens, Greece, 2014.
[18] Z. Lin, F. Ye, W. Qin, X. Cao, Y. Wang, R. Hu, R. Yan, Y. Qin, T. Yi and Z. Hong, "A low-power, wireless, real-time, wearable healthcare system," in IEEE MTT-S International Wireless Symposium (IWS), Shanghai, China, 2016.

[19] S. Chinchole, A. Kulkarni, L. Matai and C. Kotadiya, "A real-time cloud-based messaging system for delivering medication to the rural areas," in International Conference on Intelligent Sustainable Systems (ICISS), Palladam, India, 2017.

[20] H. T. Yew, M. F. Ng, S. Z. Ping, S. K. Chung, A. Chekima and J. A. Dargham, "IoT Based Real-Time Remote Patient Monitoring System," in 16th IEEE International Colloquium on Signal Processing \& Its Applications (CSPA), Langkawi, Malaysia, 2020.
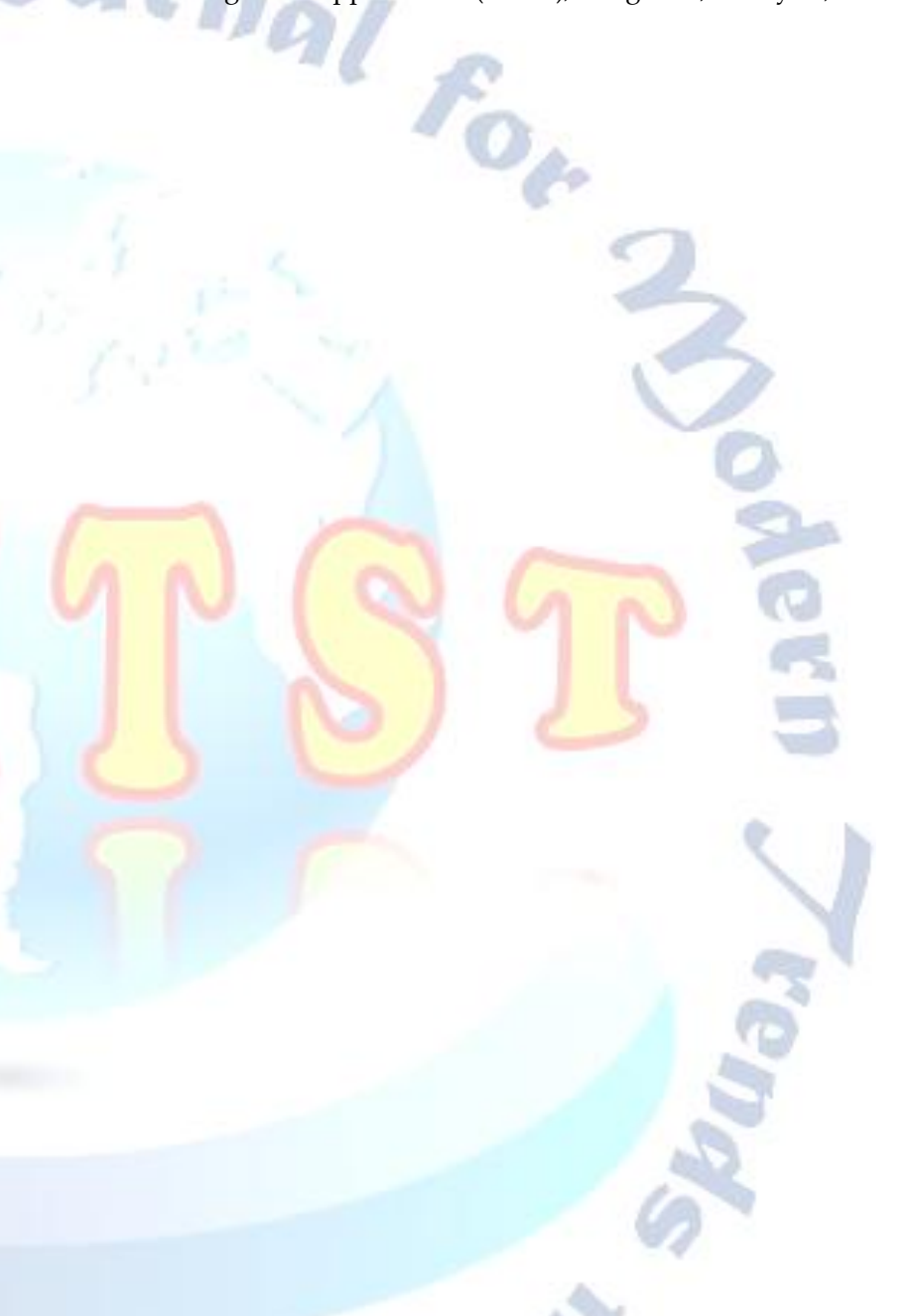

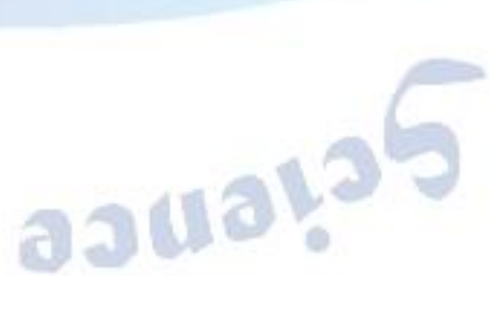

